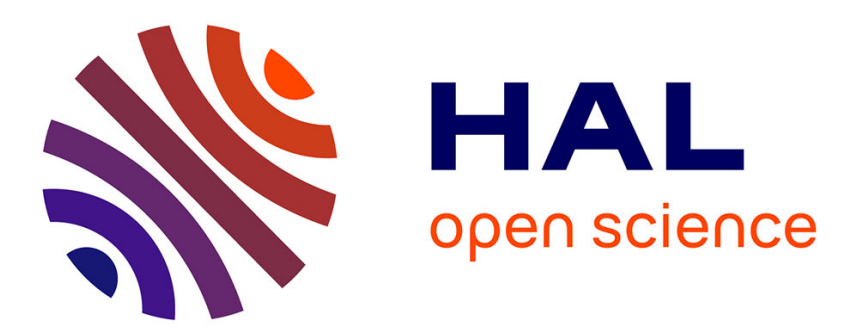

\title{
Transition to Product Service Systems: methodology based on scenarios identification, modelling and evaluation
}

Khaled Medini, Valentine Moreau, Sophie Peillon, Xavier Boucher

\section{To cite this version:}

Khaled Medini, Valentine Moreau, Sophie Peillon, Xavier Boucher. Transition to Product Service Systems: methodology based on scenarios identification, modelling and evaluation. 15th Working Conference on Virtual Enterprises (PROVE), Oct 2014, Amsterdam, Netherlands. pp.143-150, 10.1007/978-3-662-44745-1_14. hal-01058529

\section{HAL Id: hal-01058529 \\ https://hal.science/hal-01058529}

Submitted on 4 Nov 2016

HAL is a multi-disciplinary open access archive for the deposit and dissemination of scientific research documents, whether they are published or not. The documents may come from teaching and research institutions in France or abroad, or from public or private research centers.
L'archive ouverte pluridisciplinaire HAL, est destinée au dépôt et à la diffusion de documents scientifiques de niveau recherche, publiés ou non, émanant des établissements d'enseignement et de recherche français ou étrangers, des laboratoires publics ou privés. 


\title{
Transition to Product Service Systems: A Methodology based on Scenarios Identification, Modelling and Evaluation
}

\author{
Khaled Medini, Valentine Moreau, Sophie Peillon and Xavier Boucher \\ Ecole Nationale Supérieure des Mines de Saint Etienne - ENSMSE - France \\ Institut Henri Fayol \\ \{khaled.medini, moreau, peillon, boucher\}@emse.fr
}

\begin{abstract}
The paper proposes a methodology to support the organisational shift towards product Services Systems. Its backbone is the evaluation of economic impact of such a shift. However, in order to efficiently accommodate organisational changes and include company specificities, other steps are required prior to evaluation. These are context analysis, scenarios identification and modelling. The novelty of the paper lies in (i) including organisational changes in the evaluation and (ii) managing the contextualization to company specificities.
\end{abstract}

Keywords: Product Service Systems, scenarios definition, economic performance, operational performance

\section{Introduction}

The ever increasing customer specific needs coupled with increasing competition compel companies to continuously seek new business models. Among these are Product Services Systems (PSS) where customer demand is met by selling satisfaction instead of providing the product per se [1]. The transition from mere physical products to PSS can be seen as the evolution of product identity based on material content to a position where the material component is inseparable from the service system [2]. Goedkoop et al. [3] define PSS as 'a system of products, services, networks of players and supporting infrastructure that continuously strives to be competitive, satisfy customer needs and have a lower environmental impact than traditional business models'. From this, it follows that key elements of PSS are product, services, actors and combination of products and services. The identification of the combinations that satisfy all stakeholders (i.e. network of players and customer) requires evaluation of different scenarios of product and service use, in a given industrial context.

This paper proposes a methodology to support the shift towards PSS by focusing on scenarios definition and evaluation. The rest of the paper is organized as follows: Section 2 briefly reviews literature dealing with the transition to PSS. Section 3 presents the proposed methodology. An illustrative case study is presented in section 4 . 


\section{Supporting the Transition to PSS}

\subsection{PSS transition supporting methodologies}

Despite the large body of literature dealing with PSS, only a few authors addressed the question of how to shift to PSS [4]. For instance, the MEPSS (Methodology for Product Service Systems) project resulted in several guidelines supporting the shift to PSS. MEPSS provides plenty of workshop based tools intended to help companies build the PSS offer and evaluate it against sustainability criteria [5]. The mere economic evaluation is however not addressed by MEPSS. In the framework of the collaborative research project SFB/TR 29, Meier et al. [6] pointed out the importance of a solution space approach in the development of PSS rather than a single configuration. Such a solution space should be supported by a suitable organisation structure where roles are assigned to organisational units throughout the so called Industrial PSS Network. Dahmani et al. [7] proposed a framework for diagnosing the servitization potential of industrial companies from a decision point of view. Chalal et al. [8] addressed the transition to PSS at the operational level by analysing the impact of capacity management policies on the PSS performance, using simulation. Recently, Marques et al. [9] proposed a methodology for PSS development covering planning (i.e. preliminary PSS opportunities) to post-processing (i.e. preparing PSS to industrialisation) steps. Our study falls under planning and design phases of Marques et al. [9].

\subsection{Requirements of PSS supporting methodologies}

An outstanding challenge is to develop specific methodologies and tools that can provide guidelines for PSS implementation [10]. First, company strategy regarding PSS should be taken into account from the early design stages of the PSS. During the transition, companies must adapt their traditional organizational structures to cope with consumers and other stakeholders [4]. Second, it is important to involve all stakeholders in the PSS process [6] [11]. In fact, the development of the PSS recalls not only technological knowledge about products and services but also regulations and cultural backgrounds of the actors. Third, the economic viability of the PSS should be evaluated so as all stakeholders are well informed about the spins-offs and risks of the PSS. This multi-actor perspective in the decision making process has been often poorly addressed in literature. Finally, scenarios allows for putting together all pieces of puzzle: actors, products and services, thus enabling the evaluation. A scenario can be seen as a combination of product and services and actors involved. Each of the actors has a set of actions supporting the delivery of the PSS. The identification of the scenario is then a key element that shapes the organisation structure of the PSS and defines the responsibilities of the actors [11].

\section{Proposed Methodology}

This section describes a methodology to support SMEs transition towards PSS. Its steps are context analysis, usage analysis and scenarios prioritization, and scenarios 
performance evaluation (Figure 1). Steps 1 and 2 allow taking company specificities into account in a gradual way. The last step provides actors involved in PSS with good insights on the impact of the organisation changes required for delivering the PSS, through performance indicators.

\subsection{Context analysis}

The context analysis consists in understanding company's industrial context and competition factors. To determine the specific PSS issues of a company, traditional tools such as the SWOT model can be used. Moreover, PESTEL is suitable tool for analysing the external macro-environment in which the company operates. Context analysis helps identifying relevant avenues to explore so as to shift from company's current offer to an integrated PSS one.

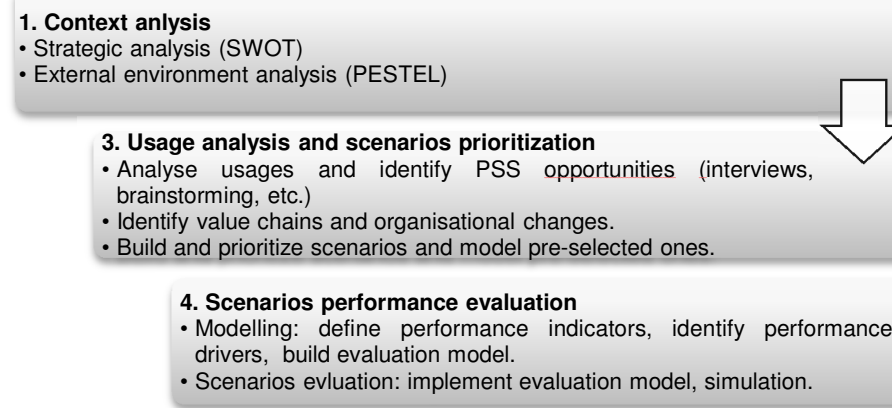

Fig.1. Proposed methodology

\subsection{Usage analysis and scenarios prioritization}

The objective of this step is to analyse different usages of the PSS offer in order to identify value creation potential for the customer and other stakeholders. To do so, it is necessary to characterize customer's categories, their usages and needs in terms of goods and services and cross these usages with PSS opportunities. Afterwards, the PSS needs to be formalized by a progressive transformation of creative ideas into welldefined scenarios. These latter provides good insights about PSS value chain. Scenarios prioritization is based on involved actors experience and external factors such as regulations and customer culture. The main challenge lies in identifying activities required to deliver the PSS and assigning organizational actors to them. This task narrows the scope of the quantitative evaluation to a limited number of scenarios, thus saving time and money.

\subsection{Scenarios performance evaluation}

The rationale of this step is to build and implement a performance evaluation model to assess the viability of the identified scenarios in terms of economic and operational performances. To do so, this step consists of 1) defining performance indicators required by each of the actors involved in the scenarios, 2) identifying physical and financial flows that needs to be modelled in order to enable indicators calculation using simulation, 3) identifying performance drivers allowing for improving the viability of 
the scenario according to actors' points of view, and finally 4) implementing the indicators to evaluate the scenarios performance. Indicators provide information about the performance of the scenarios over different time spans (e.g. monthly basis: Sales cash flow ; PSS cash flow ; Production volumes ; Supply volumes; Inventory level ; Remanufacturing, yearly basis: Sales turnover ; PSS turnover ; Annual costs; Annual margin). Although this step provides insightful information on scenarios viability, drawing conclusions on which ones to go with is still the responsibility of decision maker.

\section{Case Study}

\subsection{Context analysis}

The company under study has a business to business market in the field of quarry production plant. PSS opportunities concern a technical system and services using a laser video system to provide services for analysing physical properties of extracted stones. Market issues relate to the ownership of the product by customers, quality certification and potential of tough regulations. The internal strategic analysis underlines the viewpoints of different actors from executive committee. More important questions relate to 1) configuration of the offer and calibration of services associated and 2) understanding the internal required shift within the organization. Potential improvement areas of the current offer are quality analysis during the material extraction process and performance indicators monitoring.

\subsection{Usages analysis and scenarios prioritization (qualitative evaluation)}

Various alternatives of the technical evolution of the product issued from several meetings with the company manager and staff. Afterwards, interviews with customers took place. During these interviews customers tell their point of view about strengths and weaknesses of current offer. Then interviewers collect customers' expectation with respect to a so called "ideal offer". Afterwards, the technical possibilities raised by the company and consistent with the client's objectives are proposed. Identification of different functionalities of the product constitutes is the foundation of the role assignment, which in turn leads to scenarios building. Table 2 summarizes the assignment process of roles to actors involved in the PSS delivery. First column represents the list of services (s1 to s6) and the main functionality ensured by the PSS, that is, analyse stone properties. Second and third columns depict the actors involved, company and customer, to which are assigned roles. Scenarios sub-columns define in which scenario are the roles executed. First scenario (1) refers to PSS contracts while second one (2) refers to sales of the mere product.

Table 1. Roles assignment in the case study

\begin{tabular}{l|lc|cc}
\hline \multicolumn{1}{c|}{ Functionality/services } & \multicolumn{2}{|c}{ Company } & \multicolumn{2}{c}{ Customer } \\
& Role & Scenario & Role & Scenario \\
\hline \multirow{2}{*}{ Analyse stone properties } & Provide physical product ; Install & 1,2 & \multicolumn{2}{c}{1,2} \\
& Sell product & 1 & Use product & 1,2 \\
& Rent nroduct & 2 & &
\end{tabular}




\begin{tabular}{|c|c|c|}
\hline s1. Remove dust & Supply components ; Deliver service & 1,2 \\
\hline s2. Maintenance & Supply components ; Deliver service & 1,2 \\
\hline s3. Camera trouble shooting & Supply components ; Deliver service & 1 \\
\hline s4. Laser trouble shooting & Supply components ; Deliver service & 1 \\
\hline s5. Monitoring & Deliver service & 1,2 \\
\hline s6. Update & Deliver service & 1 \\
\hline
\end{tabular}

\subsection{Scenarios performance evaluation}

Figure 2 shows a simplified depiction of the modelled flows for the evaluation. Performance indicators that will be used for the evaluation are the following: PSS Turnover, Sales turnover, Annual costs, Annual margins, Remanufacturing, Supply volumes, and Inventory level. Performance indicators and drivers, and input parameters are depicted with boxes. Their dependencies are represented with arrows.

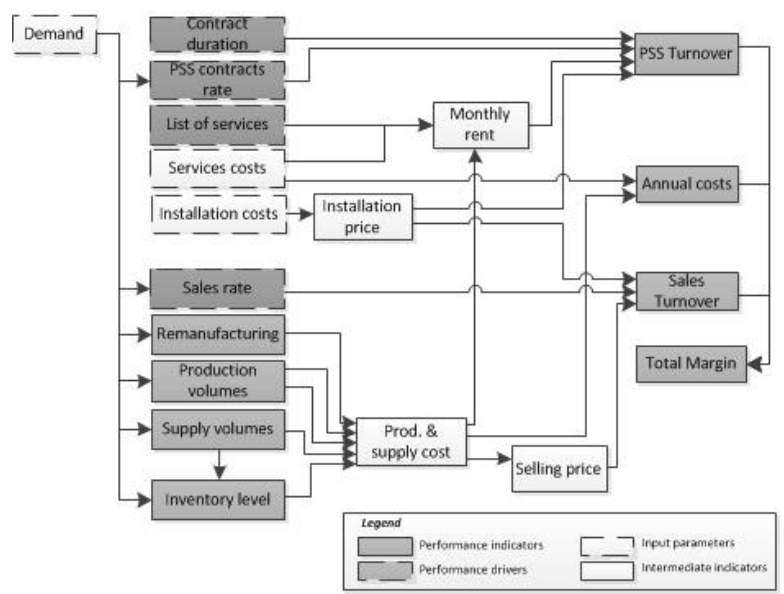

Fig.2. Quantitative modelling

Main performance drivers are: Contract duration, Distribution of PSS and sales, and services included in the PSS contracts (i.e. content of service packages). As the distribution of PSS and sales is rather demand driven, the quantitative evaluation will only focus on contract duration and services included in the PSS offer. In order to analyse the impact of these drivers on economic and operational performance, we define two sub-scenarios as follows:

- Sub-scenario 1 (ss1): input variable is contract duration $(c d)$ expressed in years, such that $c d \in\{2,4,6,8\}$.

- Sub-scenario 2 (ss2): input variable is services package $(P i)$, such that $P i \subset$ $\{s 1, s 2, s 3, s 4, s 5, s 6\}$. Accordingly, 4 situations are considered: $P 1=$ $\{s 1, s 2, s 5\}, \quad P 2=\{s 1, s 2, s 3, s 5\}, \quad P 3=\{s 1, s 2, s 3, s 4, s 5\} \quad$ and $\quad P 4=$ $\{s 1, s 2, s 3, s 4, s 5, s 6\}$.

An Excel based calculator is used for the simulation of the above scenarios. Data from the case company is gathered using interviews and internal reports.

Underlying assumptions of the simulation are as follows:

- A1: A unit of the demand is a PSS contract or a physical product sale.

- A2: The demand is increasing with $20 \%$ each year. 
- $\quad$ A3: Demand is equally balanced between PSS contracts and sales.

- A4: Simulation spans over 10 years.

- A5: Services package is fixed at $P 1$ in ss 1 simulations.

- A6: Contracts duration is fixed at 2 years in ss2 simulations.

Contract duration impact analysis. Figure 3a shows Turnovers evolution according to contract duration. Sales Turnover does not depend on such a duration, which explains that it is depicted with only one curve. An interesting result is that the longer contract duration, the higher is PSS Turnover. This can be partly explained by the reduction of installation costs which are needed when a new contract is started. It can also be seen from Figure 3a that Turnover is increasing from year 1 to 10 , which is explained by assumption A2. PSS Turnovers are more sensitive to demand increase than Sales Turnover. For example, about $20 \%$ of increase in the demand leads to an increase of PSS Turnover of 6 and 8 years contracts $(1000 \mathrm{~K} €)$ twice as much as Sales Turnover $(500 \mathrm{~K} €)$. Total variable costs have typically the same trend as Turnover. When examining Cash flow evolution during first year (Figure 3b), it is apparent that company faces a deficit during first months when offering PSS contracts. This deficit is mitigated by sales Turnover; however cash flow is still negative. This can be explained by (i) the fact that total costs exceed both PSS and Sales Turnovers, and (ii) the 3 months term of payment. Cash flow indicator is likely to compel company to seek financing so as to cover the deficit. In order to check the impact of contract duration on operational performance, we also use remanufacturing indicator. Figure $3 \mathrm{c}$ shows remanufacturing volume according to different contract durations. It points out that PSS starts to bear fruit in terms of remanufacturing, as from third year. This is expected because minimum contract duration is 2 years. Moreover Two years contracts allow for more remanufacturing, since they correspond to the highest product turnover rate.

Services packages impact analysis. Figure 3d shows the evolution of sales turnovers according to the number of offered services. An expected result is that sales turnovers and total costs increase with the number of services. Services costs are quite similar, thus the sensitivity of sales turnover is almost the same to all services (1000K€/year). In a short term perspective, increasing the number of services seems not to be interesting for the company. It could however increase customer loyalty and, thus generate economic value in the mid and long terms. Figures $3 \mathrm{e}$ and $3 \mathrm{f}$ examine the impact of services offered on the supply volumes and inventory level, respectively. Figure $3 \mathrm{e}$ points out an increase of the supplied volumes of components with the increase of services offered. This makes sense as most of the services consume components (e.g. maintenance, camera troubleshooting, etc.). This induces an increase of the inventory level, which is evident from Fig. 3f. These two indicators underline the need for a possible adaptation of the supply and storage capacities of the company, when implementing PSS. According to estimates of costs incurred by these adaptations, decision makers could choose to go ahead with investing more in services or simply offer small packages of services. Such a decision depends also on customer willingness to pay since the more services are offered, the more customers will pay. 

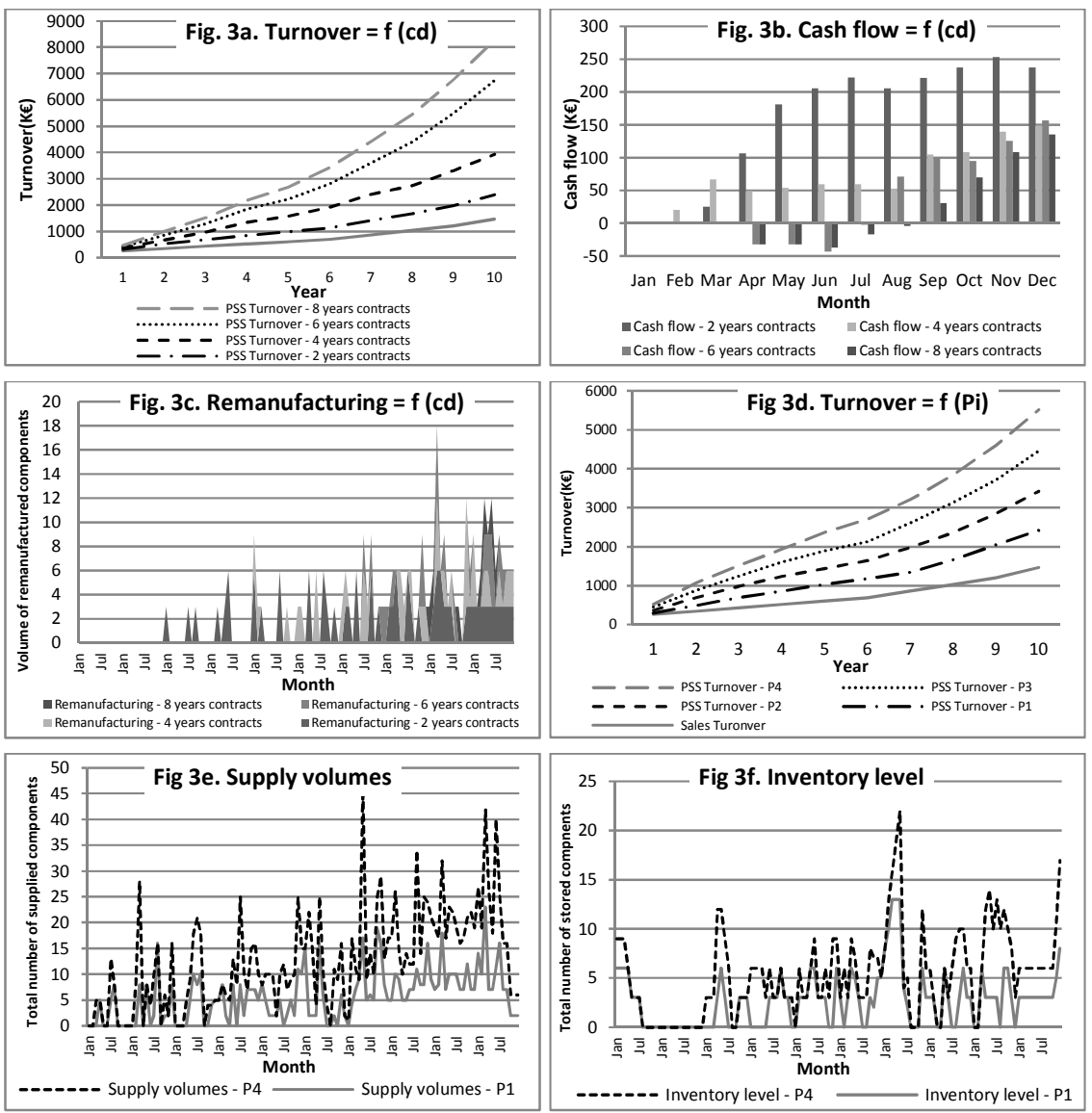

Fig.3. Simulation results

The above results provide more insight on the PSS scenario from different perspectives. However, final decision about scenario viability still requires decision maker experience which could help prioritizing the indicators. For instance, customer willingness to pay is likely to has an important weight in the decision making process.

\section{Conclusion}

The proposed methodology allows for supporting the shift towards PSS through context and usages analysis, and scenarios definition and evaluation. The design of the scenario is a key element of the methodology because it summarizes creativity efforts and usage analysis into a set of scenarios. This qualitative analysis is completed by a quantitative analysis which relies on evaluation using performance indicators and simulation. The evaluation provides more insights on scenarios viability with respect to economic and operational indicators. The case study did not, however, highlight the multi-actor aspect 
considered by the methodology. This can be further investigated using another case study where different actors are involved in the PSS delivery. Furthermore, the methodology can be generalised by enabling the possibility to adapt the performance indicators to specific industrial contexts. Another interesting improvement avenue is the integration of environmental evaluation. This helps not only evaluating environmental impact of the PSS but also identifying possible correlations or trade-offs between economic and environmental performance of the PSS.

\section{Acknowledgements}

This research has been funded by the National Research Agency (ANR ServINNOV project) and by the support of Saint-Etienne Metropole.

\section{References}

1. Meier, H., Roy, R., Seliger, G.: Industrial Product-Service Systems-IPS2. CIRP Annals Manufacturing Technology, 59(2), 607-627 (2010).

2. Baines, T. S., Lightfoot, H. W., Kay, J. M.: Servitized manufacture: Practical challenges of delivering integrated products and services. Journal of Engineering Manufacture, 223(9), 12071215 (2009).

3. Goedkoop, M. J., Halen, C. J. G., van Riele, H. R. M., Rommens, P. J. M.: Product Service systems , Ecological and Economic Basics. The Hague, NL: Dutch ministries of Environment (VROM) and Economic Affairs (EZ) (1999).

4. Beuren, F. H., Gomes Ferreira, M. G., Cauchick Miguel, P. A.: Product-service systems: a literature review on integrated products and services. Journal of Cleaner Production 47, 222-231 (2013).

5. Wimmer, R., Halen, C., Van Vezzoli, C.: Methodology for product service system innovation: how to develop clean, clever, and competitive strategies in companies. Assen. Netherlands: Koninklijke Van Gorcum (2005).

6. Meier, H., Völker O., Funke, B.: Industrial Product-Service Systems (IPS2). The International Journal of Advanced Manufacturing Technology, 52(9-12), 1175-1191 (2010).

7. Dahmani, S., Boucher, X., Peillon, S.: Industrial transition through Product-Service Systems : proposal of a decision-process modeling framework. In: Proc. of PRO-VE 2013. Springer: Dresden, Germany, 31 - 31 (2013).

8. Chalal, M., Boucher, X., Marques, G., Girard, M. A.: Managing transition towards PSS : a production system simulation approach. Proc. IPSS. Springer: Tokyo, Japan, 429 - 434 (2012).

9. Marques, P., Cunha, P.F., Valente, F., Leitão, A.: A Methodology for Product-service Systems Development, Procedia CIRP, 7, 371- 376 (2013).

10. Aurich, J. C., Mannweiler, C., Schweitzer, E.: How to design and offer services successfully. CIRP Journal of Manufacturing Science and Technology, 2(3), 136-143 (2010).

11. Morelli, N.: Developing new product service systems (PSS): methodologies and operational tools. Journal of Cleaner Production, 14(17), 1495-1501 (2006). 